\title{
Impact of preoperative diagnosis on patient satisfaction following lumbar spine surgery
}

\author{
Charles H. Crawford III, MD, ${ }^{1}$ Leah Y. Carreon, MD, MSc, ${ }^{1}$ Mohamad Bydon, MD, ${ }^{2}$ \\ Anthony L. Asher, MD, ${ }^{3}$ and Steven D. Glassman, MD ${ }^{1}$ \\ ${ }^{1}$ Norton Leatherman Spine Center, Louisville, Kentucky; ${ }^{2}$ Department of Neurosurgery, Johns Hopkins University School of \\ Medicine, Baltimore, Maryland; and ${ }^{3}$ Carolina Neurosurgery \& Spine, Charlotte, North Carolina
}

\begin{abstract}
OBJECTIVE Patient satisfaction is a commonly used metric in the current health care environment. While factors that affect patient satisfaction following spine surgery are complex, the authors of this study hypothesized that specific diagnostic groups of patients are more likely to be satisfied after spine surgery and that this is reflected in patient-reported outcome measures. The purpose of this study was to determine if the preoperative diagnosis-disc herniation, stenosis, spondylolisthesis, adjacent segment degeneration, or mechanical disc collapse-would impact patient satisfaction following surgery.
\end{abstract}

METHODS Patients enrolled in the Quality Outcomes Database, formerly known as the National Neurosurgery Quality and Outcomes Database (N2QOD), completed patient-reported outcome measures, including the Oswestry Disability Index (ODI) and Numeric Rating Scale (NRS) for back pain (NRS-BP) and leg pain (NRS-LP) preoperatively and 1-year postoperatively. Patients were stratified by diagnosis and by their response to the satisfaction question: 1) surgery met my expectations; 2) I did not improve as much as I hoped, but I would undergo the same operation for the same results; 3) surgery helped, but I would not undergo the same operation for the same results; or 4) I am the same or worse as compared with before surgery.

RESULTS A greater proportion of patients with primary disc herniation or spondylolisthesis reported that surgery met expectations (66\% and $67 \%$, respectively), followed by recurrent disc herniation and stenosis (59\% and $60 \%$, respectively). A smaller proportion of patients who underwent surgery for adjacent segment degeneration or mechanical disc collapse had their expectations met ( $48 \%$ and $41 \%$, respectively). The percentage of patients that would undergo the same surgery again, by diagnostic group, was as follows: disc herniation $88 \%$, recurrent disc herniation $79 \%$, spondylolisthesis $86 \%$, stenosis $82 \%$, adjacent segment disease $75 \%$, and mechanical collapse $73 \%$. Regardless of diagnosis, mean improvement and ultimate 1-year postoperative ODI, NRS-BP, and NRS-LP reflected patient satisfaction.

CONCLUSIONS Preoperative diagnosis was predictive of patient satisfaction following spine surgery. The mean change in and 1-year ODI, NRS-BP, and NRS-LP reflected patient satisfaction regardless of preoperative diagnosis. https://thejns.org/doi/abs/10.3171/2016.11.SPINE16848

KEY WORDS patient satisfaction; lumbar surgery; diagnosis; patient reported outcomes

$\mathrm{P}$ ATIENT satisfaction with treatment is important for all the various stakeholders in health care-patients, providers, and payers. Thus, understanding the factors that impact patient satisfaction will increase the chances that the metric will be used appropriately. These factors are undoubtedly complex. Soroceanu et al ${ }^{12}$ reported that, in addition to functional outcomes, preoperative expecta- tions and the fulfillment of expectations influence postoperative satisfaction. Chotai et al. ${ }^{4}$ reported that a Medicaid or uninsured payer status and worse baseline pain and disability scores were independent predictors of patient dissatisfaction 12 months after elective surgery for degenerative spine diseases. Abtahi et al. ${ }^{1}$ reported a significant negative association between patient satisfaction and psychological

ABBREVIATIONS BMI = body mass index; NRS-BP = Numeric Rating Scale for back pain; NRS-LP = NRS for leg pain; ODI = Oswestry Disability Index; QOD = Quality and Outcomes Database; SCB = substantial clinical benefit.

SUBMITTED July 17, 2016. ACCEPTED November 11, 2016.

INCLUDE WHEN CITING Published online March 24, 2017; DOI: 10.3171/2016.11.SPINE16848. 


\section{H. Crawford III et al.}

TABLE 1. Six lumbar disease states and their definitions for inclusion into the registry

\begin{tabular}{|c|c|}
\hline Disease State & Definition \\
\hline $\begin{array}{l}\text { Symptomatic primary lumbar } \\
\text { disc herniation }\end{array}$ & $\begin{array}{l}\text { Degenerative lumbar disc herniation that results in nerve root compression causing pain, weakness, or numbness in } \\
\text { the distribution of the affected nerve root; presence of disc herniation may be identified by MRI or CT }\end{array}$ \\
\hline $\begin{array}{l}\text { Symptomatic recurrent lumbar } \\
\text { disc herniation }\end{array}$ & $\begin{array}{l}\text { Degenerative lumbar disc herniation at the same level \& side of a prior surgical discectomy (nonfusion) that results } \\
\text { in nerve root compression that causes pain, weakness, or numbness in the distribution of the affected nerve root; } \\
\text { presence of disc herniation may be identified by MRI or CT }\end{array}$ \\
\hline Lumbar spondylolisthesis & $\begin{array}{l}\text { Grade I lumbar spondylolisthesis occurring from a congenital deformity of the pars interarticularis or from a degenera- } \\
\text { tive process associated w/ spinal canal \&/or foraminal stenosis that results in mechanical back pain \&/or radiating } \\
\text { leg pain or neurogenic claudication in the distribution of the affected nerve roots; lumbar spondylolisthesis can be } \\
\text { identified by either MRI or CT w/ an anterior or posterior slip of an adjacent vertebral body by no more than } 25 \% \text {; } \\
\text { patients w/ a slip > } 25 \% \text {, Grades II, III, \& IV spondylolisthesis are not included }\end{array}$ \\
\hline Lumbar stenosis & $\begin{array}{l}\text { Degenerative narrowing of the central, lateral recess, or foraminal lumbar spinal canal w/o listhesis or dynamic insta- } \\
\text { bility that results in nerve root compression causing pain, weakness, numbness, or neurogenic claudication in the } \\
\text { distribution of the affected nerve roots; lumbar stenosis may be identified by MRI or CT }\end{array}$ \\
\hline $\begin{array}{l}\text { Lumbar adjacent segment } \\
\text { disease }\end{array}$ & $\begin{array}{l}\text { Degenerative stenosis, listhesis, or mechanical instability of the motion segment adjacent to a prior fusion that results } \\
\text { in mechanical back pain \&/or nerve root compression that causes pain, weakness, numbness, or neurogenic clau- } \\
\text { dication in the distribution of the affected nerve roots; lumbar adjacent segment disease can be identified by MRI or } \\
\text { CT w/ or w/o dynamic plain radiographs }\end{array}$ \\
\hline $\begin{array}{l}\text { Single-level symptomatic } \\
\text { mechanical disc collapse }\end{array}$ & $\begin{array}{l}\text { Degenerative lumbar disc height loss w/o listhesis \& w/o narrowing of the lateral recess or central spinal canal (steno- } \\
\text { sis) that results in mechanical back pain w/ or w/o leg pain; back pain occurs w/ axial loading (standing/moving) \& } \\
\text { relieved by lying down; mechanical disc collapse w/o stenosis may be identified on MRI or CT; only single motion } \\
\text { segment (that is, L4-5 or L5-S1) lumbar fusion cases for this diagnosis will be included }\end{array}$ \\
\hline
\end{tabular}

Modified from McGirt et al: Neurosurg Focus 34(1):E6, 2013. Published with permission.

distress as measured by the Distress and Risk Assessment Method (DRAM) questionnaire.

The purpose of this study was to determine if patients with different preoperative diagnoses were equally satisfied after spine surgery. A secondary purpose was to determine if there were differences in outcome measures for patients within the specific diagnostic groups who were satisfied and not satisfied following spine surgery.

\section{Methods}

The Quality Outcomes Database (QOD), formerly known as the National Neurosurgery Quality and Outcomes Database $\left(\mathrm{N}^{2} \mathrm{QOD}\right)$, is a prospective multicenter quality assurance program with a substantial infrastructure to optimize data integrity and validity. The structure and methodology of the QOD registry have been reported elsewhere, ${ }^{2,10,11}$ and additional details regarding participating sites can be found online (http://www.neuropoint.org). Patient enrollment is based on well-defined diagnostic criteria including primary disc herniation, recurrent disc herniation, spondylolisthesis, stenosis, adjacent segment disease, and mechanical disc collapse. Diagnosis is based on the treating surgeon's assessment (Table 1). ${ }^{11}$ Patient outcomes data are collected in person or via telephone follow-up using standardized questionnaires. Radiographic data are not collected.

The study design was a longitudinal cohort study of patients enrolled in the QOD with at least 1 year of follow-up data. Institutional review board approval or waivers were obtained per institutional protocol. Only de-identified data were requested from the QOD. Requested data included age at surgery, diagnosis, sex, fusion versus no fusion type of surgery, Oswestry Disability Index (ODI) ${ }^{6}$ scores
(0-100 scale), EuroQOL-5D 5 scores, and Numeric Rating Scale (NRS) scores (0-10) for back pain (NRS-BP) and leg pain (NRS-LP). ${ }^{9}$ Statistical analysis was performed using IBM SPSS software version 21.0 (IBM Corp.) with significance set at $\mathrm{p}<0.01$.

Patients were stratified according to their response to the satisfaction question: surgery met my expectations; I did not improve as much as I hoped, but I would undergo the same operation for the same results; surgery helped, but I would not undergo the same operation for the same results; or I am the same or worse as compared with before surgery.

The proportion of patients in each of the following diagnostic groups was determined: primary disc herniation, recurrent disc herniation, spondylolisthesis, stenosis, mechanical disc collapse, and adjacent level degeneration.

Fisher's exact test was used to compare differences in the distribution of diagnostic etiologies among the 4 satisfaction groups. One-way ANOVA was used to determine any significant differences in the 1) change in ODI score, 2) 1-year ODI score, 3) change in NRS-BP, 4) 1-year NRS$\mathrm{BP}, 5$ ) change in NRS-LP, and 6) 1-year NRS-LP, among the 4 satisfaction groups.

\section{Results}

Of the 10,967 patients with 1-year follow-up data, 7207 (66\%) patients met study inclusion criteria. Overall, mean age was 58.94 years and mean body mass index (BMI) was $30.53 \mathrm{~kg} / \mathrm{m}^{2}$ (Table 2). Approximately $52 \%$ of the patients were male, $18 \%$ were smokers, and $48 \%$ underwent fusion surgery (Table 3). There was no statistical difference in sex distribution among the satisfaction groups ( $\mathrm{p}$ $=0.274$ ). Although age and BMI were statistically signif- 
TABLE 2. Age and BMI among the different responses to the postoperative satisfaction question

\begin{tabular}{|c|c|c|c|c|}
\hline \multirow[b]{2}{*}{ Parameter } & \multicolumn{2}{|c|}{ Age (yrs) } & \multicolumn{2}{|c|}{$\mathrm{BMI}\left(\mathrm{kg} / \mathrm{m}^{2}\right)$} \\
\hline & Mean & SD & Mean & SD \\
\hline \multicolumn{5}{|l|}{ Response } \\
\hline Surgery met my expectations & 59.49 & 14.15 & 30.28 & 6.66 \\
\hline $\begin{array}{l}\text { I did not improve as much as I } \\
\text { hoped, but I would undergo } \\
\text { same operation }\end{array}$ & 57.80 & 13.83 & 30.90 & 6.45 \\
\hline $\begin{array}{l}\text { Surgery helped, but I would } \\
\text { not undergo same opera- } \\
\text { tion }\end{array}$ & 60.34 & 13.46 & 30.97 & 6.60 \\
\hline I am the same or worse & 57.02 & 13.62 & 31.10 & 7.08 \\
\hline Overall & 58.94 & 14.02 & 30.53 & 6.66 \\
\hline$p$ value & \multicolumn{2}{|c|}{$<0.000$} & \multicolumn{2}{|c|}{$<0.000$} \\
\hline
\end{tabular}

icantly different among the response groups $(p=0.00)$, it does not appear to be a clinically relevant difference. The proportion of smokers among the different satisfaction groups was statistically significantly different, with a higher percentage of smokers in the group that responded "I am the same or worse" $(\mathrm{p}<0.000)$.

Satisfaction stratified by preoperative diagnosis is presented in Table 4. Patients with primary disc herniation or spondylolisthesis were most likely to have their expectations met (66\% and 67\%, respectively), followed by patients with recurrent disc herniation or stenosis $(59 \%$ and $60 \%$, respectively). The patients undergoing surgery for adjacent segment disease or mechanical disc collapse were least likely to have their expectations met (48\% and $41 \%$, respectively). And the patients most likely to say that they were the same or worse after surgery were those who had mechanical disc collapse (23\%). The percentage of patients that would undergo the same surgery again, by diagnostic group, was as follows: disc herniation $88 \%$, recurrent disc herniation 79\%, spondylolisthesis $86 \%$, stenosis $82 \%$, adjacent segment disease $75 \%$, and mechanical collapse $73 \%$.

Improvement in the ODI, NRS-BP, and NRS-LP scores (12-month change), as well as the ultimate 12-month postoperative scores, was highest in the patients who reported "surgery met my expectations" and lowest in the patients reporting "I am the same or worse" (Table 5).

Patients with primary disc herniation who reported "surgery met my expectations" had the best mean improvement $(36.10 \pm 19.41)$ and best ultimate $(11.78 \pm 15.34)$ ODI score, whereas patients with adjacent segment disease who reported "surgery met my expectations" had the least mean improvement $(26.81 \pm 17.09)$ and the worst ultimate $(24.02 \pm 18.61)$ ODI score (Table 6). Patients with recurrent disc herniation who reported "I did not improve as much as I hoped, but would undergo the same operation for the same results" had the best mean improvement $(21.30 \pm 19.01)$ and the best ultimate $(31.16 \pm 15.74)$ ODI score (Table 7). Patients who reported "surgery helped, but I would not undergo the same operation for the same results" had a mean improvement of $12.18 \pm 14.80$ in the
TABLE 3. Demographics among the different responses to the postoperative satisfaction question

\begin{tabular}{lcr}
\hline \multicolumn{1}{c}{ Parameter } & Smoker & \multicolumn{1}{c}{ Male } \\
\hline Response & & \\
\hline Surgery met my expectations & $656(14 \%)$ & $2354(52 \%)$ \\
\hline $\begin{array}{l}\text { I did not improve as much as I hoped, } \\
\text { but I would undergo same operation }\end{array}$ & $326(21 \%)$ & $799(51 \%)$ \\
\hline $\begin{array}{c}\text { Surgery helped, but I would not } \\
\text { undergo same operation }\end{array}$ & $96(21 \%)$ & $215(48 \%)$ \\
\hline I am the same or worse & $201(29 \%)$ & $355(52 \%)$ \\
\hline Total & $1279(18 \%)$ & $3723(52 \%)$ \\
\hline p value & $<0.000$ & 0.274 \\
\hline
\end{tabular}

ODI score and an ultimate ODI of $40.04 \pm 17.41$ (Table 8). The mean ODI improvement and ultimate ODI score were not significantly different among the diagnostic groups. Patients who reported "I am the same or worse as compared to before surgery" had mean improvement of $3.24 \pm$ 16.21 in the ODI score and an ultimate ODI score of 50.64 \pm 17.98. The mean ODI improvement and ultimate ODI score were not significantly different among the diagnostic groups (Table 9).

Smokers were less likely to have their expectations met (65\% of nonsmokers vs $51 \%$ of smokers) and twice as likely to say that they were the same or worse after surgery ( $8 \%$ of nonsmokers vs $16 \%$ of smokers; Table 3 ).

\section{Discussion}

The current study improves our understanding of patient satisfaction as it relates to preoperative diagnosis in a large, multicenter prospective database that should reflect "real world" care and therefore be generalizable. Surgeons can use the data to provide preoperative counseling to patients to set accurate preoperative expectations. Additionally, future researchers and health policy experts can use the data in the continuous attempt to improve care for the multitude of patients suffering from lumbar spinal pathology.

Our findings support the conventional wisdom that patients with well-recognized diagnoses that are frequently associated with significant radiculopathy are the most satisfied after surgery. In the current study, patients with a diagnosis of primary disc herniation or spondylolisthesis were the most likely (66\% and 67\%, respectively) to report that surgery met their expectations. They were also the most likely to report that they would undergo the same surgery for the same results ( $88 \%$ and $86 \%$, respectively) and the least likely to report being the same or worse $(8 \%$ and $7 \%$, respectively).

The group with the more difficult to define (and correlate symptoms with) diagnosis of mechanical disc collapse was the least likely to have its expectations met (41\%). Although a majority (73\%) reported that they would have the same surgery for the same results, they were the most likely $(23 \%)$ to report being "the same or worse" after surgery among the different diagnostic groups. Future studies are needed to parse out the reasons why outcomes are less consistent in the patients with mechanical disc col- 
TABLE 4. Postoperative satisfaction response stratified by preoperative diagnosis

\begin{tabular}{|c|c|c|c|c|c|c|c|}
\hline Parameter & $\begin{array}{l}\text { Primary } \\
\text { Disc } \\
\text { Herniation }\end{array}$ & $\begin{array}{l}\text { Recurrent } \\
\text { Disc } \\
\text { Herniation }\end{array}$ & Spondylolisthesis & Stenosis & $\begin{array}{l}\text { Adjacent } \\
\text { Segment } \\
\text { Disease }\end{array}$ & $\begin{array}{c}\text { Mechanical } \\
\text { Disc } \\
\text { Collapse }\end{array}$ & Total \\
\hline \multicolumn{8}{|l|}{ Response } \\
\hline Surgery met my expectations & $1611(66 \%)$ & $229(59 \%)$ & $995(66 \%)$ & $1460(60 \%)$ & $179(48 \%)$ & $27(41 \%)$ & 4501 \\
\hline $\begin{array}{l}\text { I did not improve as much as I hoped, but I would } \\
\text { undergo same operation }\end{array}$ & $539(22 \%)$ & $77(20 \%)$ & $295(20 \%)$ & $540(22 \%)$ & $99(27 \%)$ & $21(32 \%)$ & 1571 \\
\hline Surgery helped, but I would not undergo same operation & $110(4 \%)$ & $30(8 \%)$ & $94(6 \%)$ & $176(7 \%)$ & $37(10 \%)$ & $3(4 \%)$ & 450 \\
\hline I am the same or worse & $186(8 \%)$ & $49(13 \%)$ & $110(7 \%)$ & $270(11 \%)$ & $55(15 \%)$ & $15(23 \%)$ & 685 \\
\hline Total & 2446 & 385 & 1494 & 2446 & 370 & 66 & 7207 \\
\hline
\end{tabular}

$p=0.000$.

lapse. The current study was not designed to elucidate the preoperative and treatment variables within the diagnostic group that could affect outcome.

Regardless of the preoperative diagnosis, the mean change in and ultimate 1-year scores on the ODI, NRS-BP, and NRS-LP were associated with patient satisfaction. Although the scores were remarkably similar among the diagnostic groups, there were slight variations. For example, patients with adjacent segment disease whose surgical expectations had been met had slightly lower mean improvements and worse mean ultimate scores than the other diagnostic groups with the same response. This finding may indicate that the group with adjacent segment disease had lower preoperative expectations, which could have been influenced by their previous surgical experience. Patients with recurrent disc herniation who reported that they did not improve as much as they hoped but would undergo the same operation for the same results had the best mean improvement in and best ultimate ODI, which could be explained by greater preoperative expectations formed by their previous primary discectomy experience.

Interestingly, ODI, NRS-BP, and NRS-LP seem to be equally important measures in all diagnostic subgroups; for example, the disc herniation and stenosis groups also had back pain and the mechanical disc collapse group also reported leg pain. It is possible that the current patientreported outcomes do not sufficiently distinguish between what patients report as back pain and what they report as leg pain.

It is also not surprising that smokers were less likely to have their expectations met $(65 \%$ of nonsmokers vs $51 \%$ of smokers) and twice as likely to say that they were the same or worse after surgery ( $8 \%$ of nonsmokers vs $16 \%$ of smokers). Does smoking or nicotine really affect pain receptors or healing? Or is it a proxy for psychosocial factors? Previous studies have also reported smoking to be a risk factor for worse outcomes following scoliosis surgery. ${ }^{13}$

Findings in the current study provide additional support to efforts to define the substantial clinical benefit (SCB) or acceptable outcomes from the patient's perspective following surgery for degenerative lumbar conditions. In 2008 Glassman et al. ${ }^{8}$ introduced the concept of SCB in a group of patients who had undergone single-level lumbar fusion surgery. Substantial clinical benefit thresholds for the ODI (using the 0-100 scale) were an 18.8-point net improvement, a $36.8 \%$ improvement, or a final raw score $<31.3$ points. Substantial clinical benefit thresholds for the NRSBP and NRS-LP (using the 1-10 scale) were a 2.5-point net improvement or a final raw score $<3.5$ points. In the current study, those patients who reported that surgery met their expectations met the above-described thresholds with a 32.6 mean net improvement and final raw score of 14.2 on the ODI. The second tier of satisfaction-"I did

TABLE 5. Postoperative scores and changes in scores, stratified by response to satisfaction question

\begin{tabular}{|c|c|c|c|c|c|c|c|c|c|c|c|c|c|}
\hline \multirow[b]{3}{*}{ Parameter } & \multirow{3}{*}{$\begin{array}{l}\text { Total } \\
\text { No. }\end{array}$} & \multicolumn{6}{|c|}{ 12-Mo Change in Score From Preop } & \multicolumn{6}{|c|}{ 12-Mo Score } \\
\hline & & \multicolumn{2}{|c|}{ ODI } & \multicolumn{2}{|c|}{ NRS-BP } & \multicolumn{2}{|c|}{ NRS-LP } & \multicolumn{2}{|c|}{ ODI } & \multicolumn{2}{|c|}{ NRS-BP } & \multicolumn{2}{|c|}{ NRS-LP } \\
\hline & & Mean & SD & Mean & SD & Mean & SD & Mean & SD & Mean & SD & Mean & SD \\
\hline \multicolumn{14}{|l|}{ Response } \\
\hline Surgery met my expectations & 4501 & 32.66 & 18.46 & 4.34 & 3.19 & 5.41 & 3.26 & 14.20 & 15.49 & 1.84 & 2.28 & 1.40 & 2.26 \\
\hline $\begin{array}{l}\text { I did not improve as much as I hoped, } \\
\text { but I would undergo same operation }\end{array}$ & 1571 & 17.16 & 17.25 & 2.27 & 2.93 & 3.20 & 3.44 & 33.08 & 17.27 & 4.48 & 2.61 & 3.62 & 3.01 \\
\hline $\begin{array}{l}\text { Surgery helped, but I would not } \\
\text { undergo same operation }\end{array}$ & 450 & 12.18 & 14.80 & 1.74 & 2.78 & 2.46 & 3.52 & 40.04 & 17.41 & 5.23 & 2.62 & 4.47 & 3.14 \\
\hline I am the same or worse & 685 & 3.24 & 16.21 & 0.51 & 2.67 & 1.05 & 3.15 & 50.64 & 17.98 & 6.90 & 2.44 & 6.25 & 3.01 \\
\hline Overall & 7207 & 25.21 & 20.53 & 3.36 & 3.34 & 4.33 & 3.63 & 23.40 & 20.63 & 3.11 & 2.96 & 2.54 & 3.04 \\
\hline$p$ value & & \multicolumn{2}{|c|}{$<0.000$} & \multicolumn{2}{|c|}{$<0.000$} & \multicolumn{2}{|c|}{$<0.000$} & \multicolumn{2}{|c|}{$<0.000$} & \multicolumn{2}{|c|}{$<0.000$} & \multicolumn{2}{|c|}{$<0.000$} \\
\hline
\end{tabular}


TABLE 6. Postoperative scores and changes in scores in patients who answered "surgery met my expectations," stratified by diagnosis

\begin{tabular}{|c|c|c|c|c|c|c|c|c|c|c|c|c|c|}
\hline \multirow[b]{3}{*}{ Parameter } & \multirow{3}{*}{$\begin{array}{c}\text { Total } \\
\text { No. }\end{array}$} & \multicolumn{6}{|c|}{ 12-Mo Change in Score From Preop } & \multicolumn{6}{|c|}{ 12-Mo Score } \\
\hline & & \multicolumn{2}{|c|}{ ODI } & \multicolumn{2}{|c|}{ NRS-BP } & \multicolumn{2}{|c|}{ NRS-LP } & \multicolumn{2}{|c|}{ ODI } & \multicolumn{2}{|c|}{ NRS-BP } & \multicolumn{2}{|c|}{ NRS-LP } \\
\hline & & Mean & SD & Mean & SD & Mean & SD & Mean & SD & Mean & SD & Mean & SD \\
\hline \multicolumn{14}{|l|}{ Disease } \\
\hline Primary disc herniation & 1611 & 36.10 & 19.41 & 4.17 & 3.23 & 5.69 & 3.19 & 11.78 & 15.34 & 1.60 & 2.12 & 1.22 & 2.12 \\
\hline Recurrent disc herniation & 229 & 32.79 & 20.85 & 3.97 & 3.36 & 5.62 & 3.21 & 18.54 & 17.72 & 2.34 & 2.27 & 1.81 & 2.37 \\
\hline Spondylolisthesis & 995 & 32.10 & 16.56 & 4.82 & 3.06 & 5.39 & 3.22 & 14.62 & 14.33 & 1.88 & 2.24 & 1.33 & 2.19 \\
\hline Stenosis & 1460 & 29.97 & 17.73 & 4.30 & 3.20 & 5.18 & 3.31 & 14.62 & 14.88 & 1.86 & 2.37 & 1.44 & 2.30 \\
\hline Adjacent segment disease & 179 & 26.81 & 17.09 & 3.96 & 2.98 & 4.78 & 3.47 & 24.02 & 18.61 & 2.91 & 2.69 & 2.35 & 2.87 \\
\hline Disc collapse & 27 & 31.23 & 17.11 & 5.19 & 2.79 & 4.96 & 3.22 & 19.36 & 18.50 & 2.26 & 2.36 & 1.70 & 2.46 \\
\hline Overall & 4501 & 32.66 & 18.46 & 4.34 & 3.19 & 5.41 & 3.26 & 14.20 & 15.49 & 1.84 & 2.28 & 1.40 & 2.25 \\
\hline$p$ value & & \multicolumn{2}{|c|}{$<0.000$} & \multicolumn{2}{|c|}{$<0.000$} & \multicolumn{2}{|c|}{$<0.000$} & \multicolumn{2}{|c|}{$<0.000$} & \multicolumn{2}{|c|}{$<0.000$} & \multicolumn{2}{|c|}{$<0.000$} \\
\hline
\end{tabular}

not improve as much as I hoped, but would undergo the same operation for the same results" - was very near the thresholds with a 17.2 mean net improvement and final raw score of 33.1 on the ODI. It is important to note that there were significant differences between the diagnostic groups and that the standard deviations were large. Clearly, more work is needed before concepts like SCB can be applied to health policy decisions.

In 2010, Carragee and Cheng $^{3}$ reported minimum acceptable outcomes following lumbar fusion surgery, which included a decrease in pain intensity to 3/10 or less. More recently in 2016, Fekete et al. ${ }^{7}$ reported that patients were "happy to live with" a pain score $\leq 3$ on a 1 - to 10 -point scale following various surgeries for lumbar degenerative disorders. In the current study, patients reporting that surgery had met their expectations met this threshold with a final mean NRS-BP score of 1.8 and NRS-LP score of 1.4. Patients who reported less improvement than they had hoped but who would undergo the same operation for the same results were just outside of this threshold with final mean NRS-BP score of 4.5 and NRS-LP score of 3.6. Again, it is important to note that there were significant differences between the diagnostic groups and that the standard deviations were large.
There are limitations to this study. We were limited by the satisfaction questions that are already within the QOD data set, and we were unable to add other questions regarding satisfaction. A valid concern may be that some patients had low expectations for surgery and answered "surgery met my expectations" despite marginal improvement. Although plausible, it seems unlikely that a large proportion of patients would undergo surgery if their expectations for improvement were below a meaningful level. Additionally, the response "surgery met my expectations" would be chosen relative to the other 3 response choices, which appear to more clearly reflect satisfaction. The secondary analysis was performed to better understand the satisfaction categories relative to the well-accepted patient-reported outcomes of ODI, NRS-BP, and NRS-LP.

Another limitation is the incomplete follow-up, which is inherent to large registry studies. Of the 10,967 patients eligible for 1-year follow-up, only 7207 (66\%) had complete 12-month data including responses to the satisfaction question. Although a higher percentage follow-up would be ideal, the current rate of follow-up represents the best available data for a large, multiinstitutional data set that is suitable for our study question.

Another limitation is the smaller proportion of patients

TABLE 7. Postoperative scores and changes in scores in patients who answered "I did not improve as much as I hoped, but I would undergo the same operation for the same results," stratified by diagnosis

\begin{tabular}{|c|c|c|c|c|c|c|c|c|c|c|c|c|c|}
\hline \multirow[b]{3}{*}{ Parameter } & \multirow{3}{*}{$\begin{array}{c}\text { Total } \\
\text { No. }\end{array}$} & \multicolumn{6}{|c|}{ 12-Mo Change in Score From Preop } & \multicolumn{6}{|c|}{ 12-Mo Score } \\
\hline & & \multicolumn{2}{|c|}{ ODI } & \multicolumn{2}{|c|}{ NRS-BP } & \multicolumn{2}{|c|}{ NRS-LP } & \multicolumn{2}{|c|}{ ODI } & \multicolumn{2}{|c|}{ NRS-BP } & \multicolumn{2}{|c|}{ NRS-LP } \\
\hline & & Mean & SD & Mean & SD & Mean & SD & Mean & SD & Mean & SD & Mean & SD \\
\hline \multicolumn{14}{|l|}{ Disease } \\
\hline Primary disc herniation & 539 & 19.74 & 18.52 & 2.14 & 3.02 & 3.43 & 3.42 & 31.32 & 17.95 & 4.30 & 2.69 & 3.55 & 2.97 \\
\hline Recurrent disc herniation & 77 & 21.30 & 19.01 & 2.17 & 2.87 & 3.83 & 2.94 & 31.16 & 15.74 & 4.06 & 2.29 & 3.13 & 2.45 \\
\hline Spondylolisthesis & 295 & 15.73 & 15.31 & 2.74 & 2.87 & 3.36 & 3.63 & 34.82 & 16.28 & 4.51 & 2.46 & 3.55 & 3.01 \\
\hline Stenosis & 540 & 15.17 & 16.87 & 2.20 & 2.97 & 2.95 & 3.41 & 32.61 & 17.04 & 4.54 & 2.62 & 3.69 & 3.08 \\
\hline Adjacent segment disease & 99 & 15.09 & 13.55 & 2.09 & 2.27 & 2.55 & 3.40 & 40.02 & 16.33 & 5.25 & 2.59 & 4.18 & 3.17 \\
\hline Disc collapse & 21 & 16.73 & 18.12 & 2.43 & 2.69 & 2.43 & 3.12 & 40.12 & 18.38 & 5.14 & 2.58 & 4.10 & 3.18 \\
\hline Overall & 1571 & 17.16 & 17.25 & 2.27 & 2.93 & 3.20 & 3.44 & 33.08 & 17.27 & 4.48 & 2.61 & 3.62 & 3.01 \\
\hline$p$ value & & \multicolumn{2}{|c|}{$<0.000$} & \multicolumn{2}{|c|}{0.093} & \multicolumn{2}{|c|}{0.022} & \multicolumn{2}{|c|}{$<0.000$} & \multicolumn{2}{|c|}{0.011} & \multicolumn{2}{|c|}{0.236} \\
\hline
\end{tabular}


TABLE 8. Postoperative scores and changes in scores in patients who answered "surgery helped, but I would not undergo the same operation for the same results," stratified by diagnosis

\begin{tabular}{|c|c|c|c|c|c|c|c|c|c|c|c|c|c|}
\hline \multirow[b]{3}{*}{ Parameter } & \multirow{3}{*}{$\begin{array}{l}\text { Total } \\
\text { No. }\end{array}$} & \multicolumn{6}{|c|}{ 12-Mo Change in Score From Preop } & \multicolumn{6}{|c|}{ 12-Mo Score } \\
\hline & & \multicolumn{2}{|c|}{ ODI } & \multicolumn{2}{|c|}{ NRS-BP } & \multicolumn{2}{|c|}{ NRS-LP } & \multicolumn{2}{|c|}{ ODI } & \multicolumn{2}{|c|}{ NRS-BP } & \multicolumn{2}{|c|}{ NRS-LP } \\
\hline & & Mean & SD & Mean & SD & Mean & SD & Mean & SD & Mean & SD & Mean & SD \\
\hline \multicolumn{14}{|l|}{ Disease } \\
\hline Primary disc herniation & 110 & 13.19 & 16.84 & 1.47 & 2.93 & 2.69 & 2.98 & 37.98 & 18.61 & 5.14 & 2.58 & 4.28 & 2.96 \\
\hline Recurrent disc herniation & 30 & 16.94 & 16.92 & 1.60 & 3.70 & 1.53 & 4.15 & 40.35 & 17.15 & 5.23 & 2.98 & 5.83 & 2.70 \\
\hline Spondylolisthesis & 94 & 12.14 & 13.69 & 2.14 & 2.47 & 2.82 & 3.93 & 41.46 & 14.65 & 5.33 & 2.41 & 4.01 & 3.05 \\
\hline Stenosis & 176 & 10.96 & 13.66 & 1.76 & 2.81 & 2.16 & 3.58 & 38.27 & 17.61 & 4.97 & 2.66 & 4.47 & 3.25 \\
\hline Adjacent segment disease & 37 & 10.61 & 14.61 & 1.54 & 2.21 & 3.00 & 3.06 & 50.43 & 16.81 & 6.41 & 2.60 & 5.05 & 3.54 \\
\hline Disc collapse & 3 & 19.11 & 7.00 & 2.67 & 0.58 & 2.33 & 2.08 & 43.56 & 4.82 & 6.33 & 1.15 & 5.33 & 1.53 \\
\hline Overall & 450 & 12.18 & 14.80 & 1.74 & 2.78 & 2.46 & 3.52 & 40.04 & 17.41 & 5.23 & 2.62 & 4.47 & 3.14 \\
\hline$p$ value & & \multicolumn{2}{|c|}{0.318} & \multicolumn{2}{|c|}{0.619} & \multicolumn{2}{|c|}{0.344} & \multicolumn{2}{|c|}{0.004} & \multicolumn{2}{|c|}{0.075} & \multicolumn{2}{|c|}{0.088} \\
\hline
\end{tabular}

TABLE 9. Postoperative scores and changes in scores in patients who answered "I am the same or worse as compared to before surgery," stratified by diagnosis

\begin{tabular}{|c|c|c|c|c|c|c|c|c|c|c|c|c|c|}
\hline \multirow[b]{3}{*}{ Parameter } & \multirow{3}{*}{$\begin{array}{c}\text { Total } \\
\text { No }\end{array}$} & \multicolumn{6}{|c|}{ 12-Mo Change in Score From Preop } & \multicolumn{6}{|c|}{ 12-Mo Score } \\
\hline & & \multicolumn{2}{|c|}{ ODI } & \multicolumn{2}{|c|}{ NRS-BP } & \multicolumn{2}{|c|}{ NRS-LP } & \multicolumn{2}{|c|}{ ODI } & \multicolumn{2}{|c|}{ NRS-BP } & \multicolumn{2}{|c|}{ NRS-LP } \\
\hline & & Mean & SD & Mean & SD & Mean & SD & Mean & SD & Mean & SD & Mean & SD \\
\hline \multicolumn{14}{|l|}{ Disease } \\
\hline Primary disc herniation & 186 & 4.00 & 18.89 & 0.31 & 2.57 & 1.32 & 3.19 & 48.65 & 18.03 & 6.98 & 2.38 & 6.28 & 2.90 \\
\hline Recurrent disc herniation & 49 & 3.45 & 16.36 & 0.43 & 2.38 & 0.31 & 2.51 & 55.90 & 15.96 & 7.06 & 2.15 & 7.16 & 2.15 \\
\hline Spondylolisthesis & 110 & 3.86 & 16.80 & 0.75 & 2.45 & 0.86 & 3.56 & 50.02 & 17.84 & 6.82 & 2.42 & 5.73 & 3.28 \\
\hline Stenosis & 270 & 2.44 & 14.65 & 0.58 & 2.95 & 1.15 & 3.17 & 49.70 & 17.81 & 6.75 & 2.53 & 6.19 & 3.05 \\
\hline Adjacent segment disease & 55 & 2.37 & 12.41 & 0.29 & 2.35 & 0.69 & 2.35 & 57.58 & 18.01 & 7.27 & 2.55 & 6.78 & 2.90 \\
\hline Disc collapse & 15 & 6.09 & 15.94 & 0.87 & 2.07 & 1.00 & 3.46 & 54.27 & 20.66 & 7.33 & 1.95 & 5.93 & 3.51 \\
\hline Overall & 685 & 3.24 & 16.21 & 0.51 & 2.67 & 1.05 & 3.15 & 50.64 & 17.98 & 6.90 & 2.44 & 6.25 & 3.01 \\
\hline$p$ value & & \multicolumn{2}{|c|}{0.870} & \multicolumn{2}{|c|}{0.718} & \multicolumn{2}{|c|}{0.358} & \multicolumn{2}{|c|}{0.006} & \multicolumn{2}{|c|}{0.656} & \multicolumn{2}{|c|}{0.079} \\
\hline
\end{tabular}

in the diagnostic groups with lower satisfaction (that is, recurrent disc herniation, adjacent segment disease, and mechanical disc collapse). The distribution reflects the real-world practice of the contributing surgeons and to some extent may reflect their willingness to offer surgery for these diagnoses. On the other hand, it may reflect a lower prevalence of these diagnoses in the general population. The statistical and clinical significance of the study findings should be viewed in light of this limitation. Finally, duration of follow-up may be considered another limitation. The QOD was designed and/or implemented with a target 1-year follow-up. Two-year follow-up is only available for a small number of sites participating in the QOD.

\section{Conclusions}

In summary, the current study improves our understanding of patient-reported outcome measures and patient satisfaction following lumbar spinal surgery for degenerative pathologies. Psychosocial factors, including smoking, continue to show clinical significance across multiple studies and may be important to consider in future health policy decisions. Data in the current study may help surgeons set accurate preoperative expectations for their pa- tients and serve as a baseline to which individual postoperative outcomes can be compared.

\section{References}

1. Abtahi AM, Brodke DS, Lawrence BD, Zhang C, Spiker WR: Association between patient-reported measures of psychological distress and patient satisfaction scores after spine surgery. J Bone Joint Surg Am 97:824-828, 2015

2. Asher AL, Speroff T, Dittus RS, Parker SL, Davies JM, Selden N, et al: The National Neurosurgery Quality and Outcomes Database ( $\left.{ }^{2} \mathrm{QOD}\right)$ : a collaborative North American outcomes registry to advance value-based spine care. Spine (Phila Pa 1976) 39 (22 Suppl 1):S106-S116, 2014

3. Carragee EJ, Cheng I: Minimum acceptable outcomes after lumbar spinal fusion. Spine J 10:313-320, 2010

4. Chotai S, Sivaganesan A, Parker SL, McGirt MJ, Devin CJ: Patient-specific factors associated with dissatisfaction after elective surgery for degenerative spine diseases. Neurosurgery 77:157-163, 2015

5. EuroQol Group: EuroQol-a new facility for the measurement of health-related quality of life. Health Policy 16:199208, 1990

6. Fairbank JC, Pynsent PB: The Oswestry Disability Index. Spine (Phila Pa 1976) 25:2940-2952, 2000

7. Fekete TF, Haschtmann D, Kleinstück FS, Porchet F, Jeszen- 
szky D, Mannion AF: What level of pain are patients happy to live with after surgery for lumbar degenerative disorders? Spine J 16 (4 Suppl):S12-S18, 2016

8. Glassman SD, Copay AG, Berven SH, Polly DW, Subach BR, Carreon LY: Defining substantial clinical benefit following lumbar spine arthrodesis. J Bone Joint Surg Am 90:18391847, 2008

9. McCaffery M, Beebe A: Pain: Clinical Manual for Nursing Practice. Baltimore: V.V. Mosby Company, 1993

10. McGirt MJ, Parker SL, Asher AL, Norvell D, Sherry N, Devin CJ: Role of prospective registries in defining the value and effectiveness of spine care. Spine (Phila Pa 1976) 39 (22 Suppl 1):S117-S128, 2014

11. McGirt MJ, Speroff T, Dittus RS, Harrell FE Jr, Asher AL: The National Neurosurgery Quality and Outcomes Database $\left(\mathrm{N}^{2} \mathrm{QOD}\right)$ : general overview and pilot-year project description. Neurosurg Focus 34(1):E6, 2013

12. Soroceanu A, Ching A, Abdu W, McGuire K: Relationship between preoperative expectations, satisfaction, and functional outcomes in patients undergoing lumbar and cervical spine surgery: a multicenter study. Spine (Phila Pa 1976) 37:E103-E108, 2012

13. Spanyer JM, Crawford CH III, Canan CE, Burke LO, Carreon LY: Health-related quality-of-life scores, spine-related symptoms, and reoperations in young adults 7 to 17 years after surgical treatment of adolescent idiopathic scoliosis. Am J Orthop (Belle Mead NJ) 44:26-31, 2015

\section{Disclosures}

Dr. Carreon is a consultant for AO Spine; has received support from OREF, Norton Healthcare, and SRS for non-study-related clinical or research effort; and has received funds for travel from the University of Southern Denmark and the University of Louisville. Dr. Crawford is consultant for Alphatec and Medtronic and has had teaching/speaking engagements at Titan Spine. Dr. Glassman is a consultant for, holds a patent with, and receives royalties from Medtronic.

\section{Author Contributions}

Conception and design: Crawford, Glassman. Acquisition of data: all authors. Analysis and interpretation of data: Carreon, Glassman. Drafting the article: Crawford. Critically revising the article: all authors. Reviewed submitted version of manuscript: all authors. Approved the final version of the manuscript on behalf of all authors: Carreon. Statistical analysis: Carreon. Administrative/ technical/material support: Asher, Glassman. Study supervision: Asher.

\section{Correspondence}

Leah Y. Carreon, Norton Leatherman Spine Center, 210 East Gray St., Ste. 900, Louisville, KY 40202. email: leah.carreon@ nortonhealthcare.org. 